\title{
Bilateral split hand and split foot malformation in a boy with a de novo interstitial deletion of $7 \mathrm{q} 21.3$
}

\author{
S H Roberts, H E Hughes, S J Davies, A L Meredith
}

\begin{abstract}
A case of bilateral split hand and split foot malformation is reported in a boy with a complex rearrangement of chromosome 7 including a de novo interstitial deletion of 7q21.3.
\end{abstract}

The apparent association between interstitial deletion of the proximal long arm of chromosome 7 involving $7 \mathrm{q} 21$ and ectrodactyly (split hand/split foot malformation) was recognised in 1989 by Tajara et al, ${ }^{1}$ who reported a case and found two similar published cases. ${ }^{2}{ }^{3}$ Subsequently, Morey and Higgins ${ }^{4}$ described amelia and ectrodactyly associated with an interstitial deletion of 7q. We describe here a boy with bilateral ectrodactyly of the hands and feet and a de novo interstitial deletion of $7 \mathrm{q} 21.3$.

\section{Case report}

A male infant was delivered at 35 weeks by caesarian section for pre-eclampsia. The mother and father, aged 24 and 27, respectively, were healthy and nonconsanguineous. There was a history of two previous first trimester spontaneous abortions. The mother did not drink alcohol or smoke during pregnancy. Folic acid was given from 6 weeks' gestation. Birth weight was $2200 \mathrm{~g}$. The Apgar score was 5 at one minute, 6 at five minutes, and 10 at 10 minutes. Intubation was not required. Ectrodactyly was noted in all four limbs. Examination at 5 years showed that the median ray was absent in both hands. The right foot was monodactylous and digits 2 and 3 were absent in the left foot (fig 1). His height was below the 3rd centile

\footnotetext{
Institute of Medical Genetics, University Hospital of Wales, Heath Park, Cardiff CF4 4XN.

S H Roberts, H E Hughes, S J Davies, A L Meredith Correspondence to $\mathrm{Mr}$ Roberts.
}

Received for publication 15 October 1990.

Revised version accepted for publication 4 December 1990. and his weight was just above the 3rd centile. Head circumference was on the 50th centile. There were mild dysmorphic features: relative hypertelorism with epicanthic folds, posterior rotation of the ears, and fixed flexion of the helices. The hair, teeth, and nails were normal, and the palate was intact. A renal ultrasound investigation was normal. On full developmental assessment at the age of 6 his full scale IQ was 84 (15th centile), verbal IQ was 72 (4th centile), and performance IQ was 100 (50th centile). He now requires special schooling for delayed speech.

\section{CYTOGENETIC STUDIES}

High resolution GTG and RBG banding studies showed a complex intrachromosomal rearrangement of chromosome 7, which included an interstitial deletion of sub-band 7q21.3 (fig 2). Detailed examination showed that, although the $\mathrm{p}$ arm was longer and the $\mathrm{q}$ arm shorter than normal, the banding pattern was not consistent with a pericentric inversion. Rather, there appeared to be an insertion of material from the proximal long arm into the short arm at p15.1. Furthermore, band q21 was narrower than normal, owing to the loss of q21.3 (fig 3). The karyotype was therefore interpreted as $46, \mathrm{XY}$, ins (7), $\operatorname{del}(7)($ pter $\rightarrow$ p15.1::q11.21 $\rightarrow$ q11.23::p15.1 $\rightarrow$ q21.2:: q22.1 $\rightarrow$ qter). The parental karyotypes were normal.

A cell line from this patient has not yet been established.

\section{DNA STUDIES}

DNA analysis using RFLPs for three probes, pXV2C, pKM19, and cDNA for the MET proto-oncogene, which are closely linked to the cystic fibrosis locus, failed to show hemizygosity, confirming that they map outside the deletion.

\section{Discussion}

Ectrodactyly is characterised by the congenital absence of one or more median rays or digits, often with 


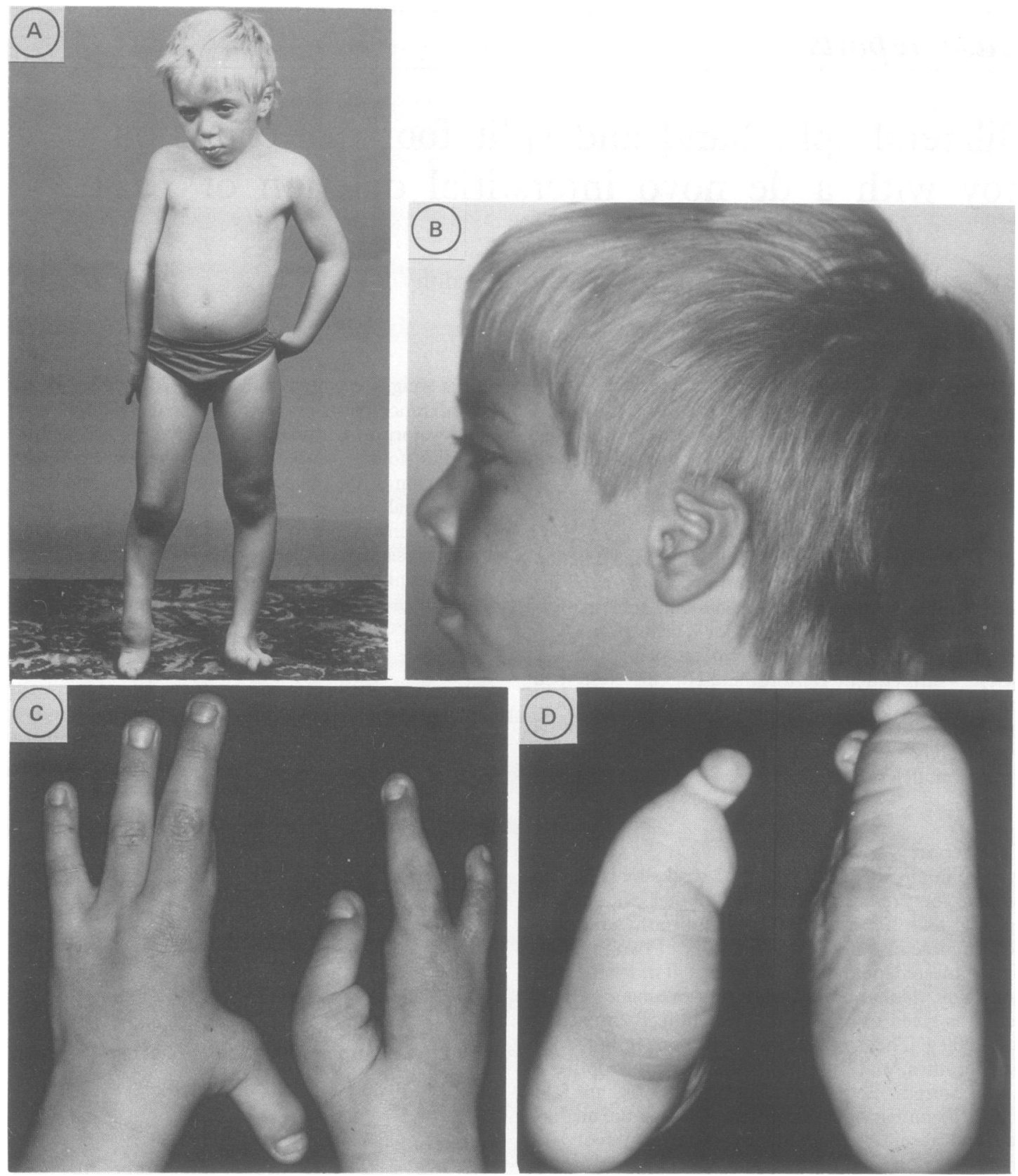

Figure 1 Proband at 5 years: $(A)$ whole body; (B) side view of head showing flexion deformity of ear; $(C)$ hands; $(D)$ feet.

syndactyly of the remaining digits, which results in the split hand/split foot malformation. This can be unilateral or bilateral, involving hands or feet or both. The majority of cases are sporadic but familial cases usually show an autosomal dominant mode of inheri- tance with reduced penetrance. A single gene defect is therefore probably responsible. There have been four previous reports of ectrodactyly associated with interstitial deletion of $7 q$ involving band $q 21 .{ }^{1-4}$ A causal relationship must be presumed to exist, 

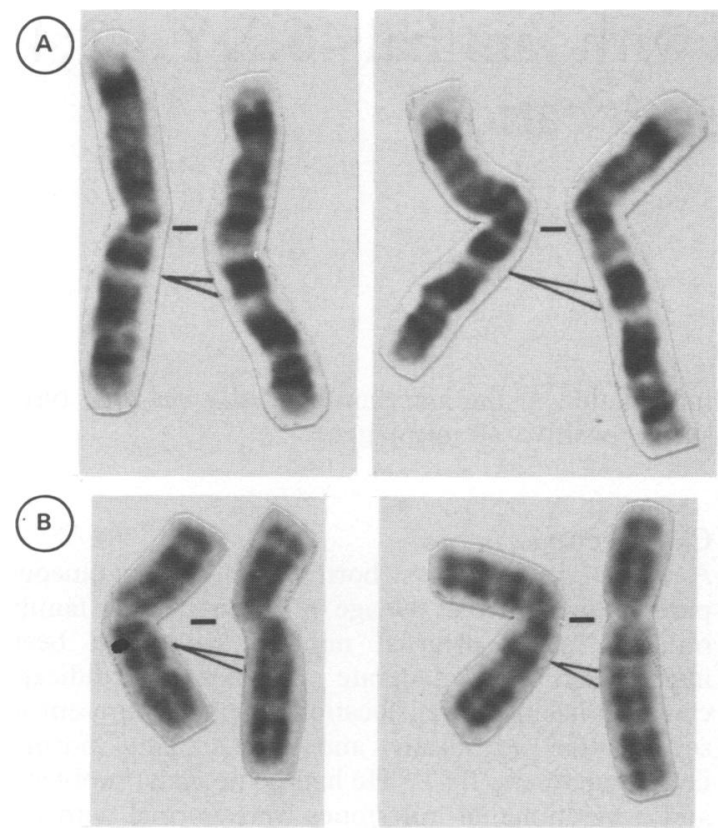

Figure 2 (A) GTG and (B) RBG banding of two pairs of chromosomes 7 from the proband; the abnormal chromosome is on the left in each pair. The position of the deleted segment is indicated.

although cases with deletions of chromosome 7 apparently involving q21 but without ectrodactyly have been reported. ${ }^{5}$ In the present case the association of bilateral ectrodactyly with the interstitial deletion of 7q21.3 appears to localise the gene for ectrodactyly to this sub-band. DNA analysis now offers the prospect of identifying the gene.

1 Tajara EH, Varella-Garcia M, Gusson ACT. Interstitial long-arm

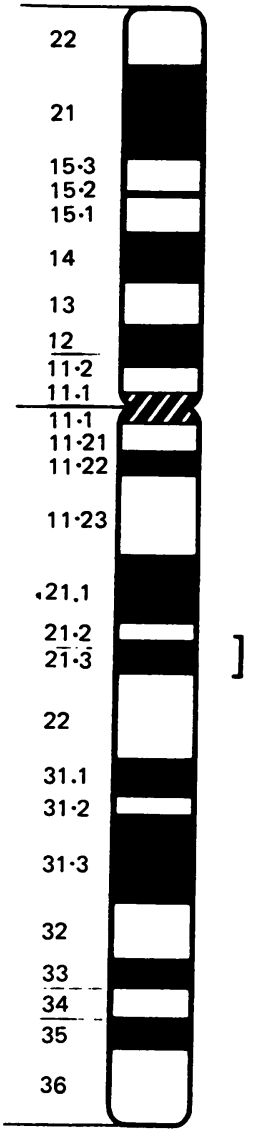

Figure 3 Diagram of chromosome 7 showing the location of the deleted segment.

deletion of chromosome 7 and ectrodactyly. Am 7 Med Genet 1989;32:192-4.

2 Del Porto G, D'Alessandro E, De Matteis C, Lo Re ML, Ivaldi $M$, Di Fusco C. Delezione interstiziale del braccio lungo del cromosoma 7 e sue correlazioni cliniche. Pathologica (Suppl) 1983;75:268-71.

3 Pfeiffer RA. Interstitial deletion of a chomosome 7 (q11.2q22.1) in a child with splithand/splitfoot malformation. Ann Genet (Paris) 1984;27:45-8.

4 Morey AM, Higgins RR. Ectro-amelia syndrome associated with an interstitial deletion of 7q. Am F Med Genet 1990;35:95-9.

5 Schinzel A. Catalogue of unbalanced chromosome aberrations in man. Berlin: Walter de Gruyter, 1984. 